\title{
Ação intersetorial: potencialidades e dificuldades do trabalho em equipes da Estratégia Saúde da Família na cidade do Rio de Janeiro
}

\author{
Intersectoral action: potentialities and difficulties of working in teams \\ under the project Family Health Strategy in the city of Rio de Janeiro
}

Denise Alves José da Silva', Maria de Fátima Lobato Tavares²

RESUMO A intersetorialidade é uma ação de promoção da saúde modificadora dos determinantes sociais de saúde. O objetivo deste estudo foi o de analisar ações intersetoriais a partir da percepção das equipes de saúde de uma unidade de saúde da cidade do Rio de Janeiro. Optouse pela pesquisa qualitativa, aplicando-se entrevistas semiestruturadas e observação direta. Os resultados revelam frágil planejamento, monitoramento e avaliação de ações; a gestão e o controle social mostraram-se pouco efetivos e observou-se baixa participação popular; trabalho interequipe e intersetorial desarticulado; formação não focada na interdisciplinaridade. A equipe construiu proposições para reorientar práticas e fomentar ações intersetoriais na lógica da saúde ampliada.

PALAVRAS-CHAVE Ação intersetorial. Promoção da saúde. Saúde da família. Equipe de assistência ao paciente.

ABSTRACT The intersectoral approach is a health promotion action modifying of the social determinants of health. The objective of this study was to analyze intersectoral actions grounded on the perception of the health teams composing a health unit located in the city of Rio de Janeiro. We opted for the qualitative research, in which semi-structured interviews and direct observation were adopted. The results reveal fragile planning, monitoring and evaluation of actions; management and social control have proved little effective, and low public participation was also observed; the inter team and intersectoral work was disjointed; training did not focus on interdisciplinarity. The teamwork built propositions so to reorient practices and promote intersectoral

1 Secretaria Municipal de Saúde (SMS) - Rio de Janeiro (RJ), Brasil. denisealvesjs@gmail.com

2 Fundação Oswaldo Cruz (Fiocruz), Escola Nacional de Saúde Pública Sergio Arouca (Ensp), Departamento de Administração e Planejamento em Saúde Rio de Janeiro (RJ), Brasil. flobato@ensp.fiocruz.br expanded health logic.

KEYWORDS Intersectoral action. Health promotion. Family health. Patient care team. 


\section{Introdução}

A ação intersetorial para a Equipe de Saúde da Família (EqSF) representa um grande desafio na articulação e planejamento do processo de trabalho. O diálogo intersetorial é difícil, pois requer respeitar a visão do outro e sua contribuição para a construção de decisões no enfrentamento dos problemas e situações levantados, sendo uma estratégia importante de reconstrução das práticas de saúde. Desenvolver esse tipo de prática é concretizar uma atuação com o olhar ampliado na abordagem do processo saúde-doença-cuidado, implementando ações de promoção da saúde com enfrentamento e mudança sobre os Determinantes Sociais da Saúde (DSS) (CNDSS, 2008).

O trabalho intersetorial desponta como instrumento relevante para a operacionalização do conceito ampliado de saúde e de ações com base nos pressupostos teóricos e metodológicos da promoção da saúde. É uma ação chave no trabalho em equipe na Estratégia Saúde da Família (ESF).

Junqueira (2000, P. 42) definiu intersetorialidade como

a articulação de saberes e experiências no planejamento, realização e avaliação de ações para alcançar efeitos sinérgicos em situações complexas visando o desenvolvimento social, superando a exclusão social.

A intersetorialidade então é trazida para o centro do debate e sua prática requer ampla negociação, alcançando dimensão transetorial a partir das possibilidades de criar novos olhares e instaurar novos valores. Deve considerar o respeito às diferenças e à incorporação das contribuições de cada uma das políticas na compreensão e na superação dos problemas sociais. Tem em sua lógica central a operacionalização de conceitos como a territorialização, vinculação, responsabilização e resolutividade com um olhar integral sobre o ambiente em suas dimensões físicas, socioculturais e biopsicossociais, nas quais estão inseridos os indivíduos e suas famílias (JUNQUEIRA, 2000).

A discussão da promoção da saúde cresceu no Brasil nas últimas duas décadas, fazendo surgir vários projetos institucionais no âmbito do Sistema Único de Saúde (SUS). Em 2006 é aprovada a Política Nacional de Promoção da Saúde (PNPS) que reafirma a relevância do setor saúde trazendo como objetivo a promoção da qualidade de vida e a redução de vulnerabilidade e riscos à saúde relacionados aos seus determinantes e condicionantes - modos de viver, condições de trabalho, habitação, ambiente, educação, lazer, cultura, acesso a bens e serviços essenciais (BRASIL, 2010).

A PNPS (BRASIL, 2014) reelaborada compreende o princípio da intersetorialidade como uma articulação de saberes e práticas de sujeitos, grupos e setores mobilizados na formulação de políticas públicas e intervenções compartilhadas, assumindo corresponsabilização pela garantia de objetivos comuns, dentre esses, a saúde e a cidadania que são direitos humanos. Para tanto, faz-se necessário desenvolver processos participativos que promovam o desenvolvimento da capacidade dos indivíduos de controlar situações a partir da conscientização dos determinantes dos problemas ou da formação do pensamento crítico (MARTINS, 2009). A Portaria $\mathrm{n}^{\mathrm{o}}$ 2.446/2014 apresentou como valores fundantes para sua efetivação: solidariedade, felicidade, respeito às diversidades, ética, humanização, corresponsabilidade, justiça social e inclusão social.

$\mathrm{O}$ trabalho em equipe e a interdisciplinaridade são características do processo de trabalho da ESF que muito contribuíram para a renovação do modelo de atenção à saúde. No contexto da saúde o axioma da interdisciplinaridade é o processo saúde-doença-cuidado, constituindo-se em permanente troca de conhecimentos com articulação no campo de produção do cuidado no cotidiano das práticas, de forma a reafirmar o trabalho em equipe (FRANCO; MERHY, 1999). 
O trabalhador de saúde reconhece que é na alteridade, na diferença do outro, incluindo equipe e usuário, que se consegue construir um projeto comum, com diferentes olhares (MANCE, 1994). O trabalho de equipe facilita a construção das redes que podem ser definidas como trabalho coletivo, articulação de diversos sujeitos, com conhecimentos e habilidades para produzir transformações. Nessa dimensão, encontram-se os conceitos de campo e núcleo. O núcleo é o conjunto de saberes e responsabilidades específicos de cada profissão, enquanto o campo são os saberes e responsabilidades de várias profissões ou especialidades que podem ser compartilhados (MENDONÇA, 2007).

Fica evidente, então, o desafio da implementação da intersetorialidade - um dos princípios da ESF - associada a um trabalho em equipe com corresponsabilidade entre a saúde e os outros setores, possibilitando troca de saberes, planejamento de ações e tomada de decisões de forma compartilhada. Assim, a intersetorialidade incorpora a ideia de integração, de território, de equidade, de direitos sociais e outros. Esse novo fazer demanda mudanças de valores da cultura para um agir coletivo.

Este artigo é resultado da dissertação de mestrado intitulada 'Ação intersetorial: potencialidades e dificuldades do processo de trabalho em equipe na Estratégia Saúde da Família'. A dissertação abordou o processo de desenvolvimento das ações intersetoriais pelas EqSFs de uma Unidade Básica de Saúde (UBS) do município do Rio de Janeiro e a importância da articulação de tais ações com o trabalho em equipe e sua influência sobre a mobilização e participação social. Teve como um de seus objetivos analisar os fatores e mecanismos facilitadores e restritivos à implementação das ações intersetoriais e à sustentabilidade das iniciativas de promoção da saúde a partir das percepções dos profissionais de uma EqSF.

\section{Metodologia}

Este estudo possui caráter exploratório e abordagem qualitativa. Possibilitou identificar a percepção dos trabalhadores sobre o desenvolvimento das ações intersetoriais no contexto do processo de trabalho de uma UBS com modelo de atenção de cobertura universal pela ESF localizada na cidade do Rio de Janeiro. Desenvolveu-se em três fases, a primeira tratou do levantamento bibliográfico, a segunda ocupou-se da pesquisa de campo propriamente dita e a última fase deteve-se na avaliação e análise dos dados qualitativos.

$\mathrm{Na}$ aplicação dos instrumentos de pesquisa, utilizou-se a abordagem de triangulação de técnicas, obtendo assim, um olhar sob várias dimensões da pesquisa. Os dados empíricos foram originados dos instrumentos aplicados aos pesquisados, entrevistas semiestruturadas e observação direta realizados no período de janeiro a março de 2013. A pesquisa não se orientou pelo critério de saturação, pois o objeto de estudo não era estranho à pesquisadora, e porque foi possível perceber o desejo de todos os profissionais de deixar sua fala registrada, decisão que não comprometeu os resultados da pesquisa.

Foram elaborados três roteiros para as entrevistas, de acordo com o perfil do profissional. Um modelo foi destinado ao gestor, aqui também na figura do informante privilegiado, necessário para completar e enriquecer a informação recolhida das várias fontes; outro aos profissionais das equipes de nível superior; e o último para profissionais das equipes de nível técnico. A condução do roteiro obedeceu à seguinte organização: a) levantamento da competência técnica; b) concepção de promoção da saúde; c) processo do trabalho em equipe; d) participação e representação comunitária; e) percepção e concepção sobre ação intersetorial.

A pesquisa contou com 34 participantes. Cada EqSF estava composta por médico, enfermeiro, técnico de enfermagem, agente de 
vigilância em saúde e Agente Comunitário de Saúde (ACS). As equipes de saúde bucal eram compostas cada uma com um cirurgião-dentista e um auxiliar de saúde bucal, e uma das equipes também possuía um técnico de saúde bucal. No período das entrevistas, as equipes estavam incompletas, compostas por dois médicos com carga horária de 40 horas, um médico 20 horas e com 14 ACS. Todos os profissionais aceitaram participar da pesquisa. Os dados foram gravados, após comunicação e autorização do entrevistado e transcritos com garantia de sigilo.

Quanto à técnica de observação direta, aplicou-se a não estruturada e assistemática, que considerou o mínimo de interferência na pesquisa. De acordo com Minayo (2010, P. 277):

A atitude de observador científico consiste em colocar-se do ponto de vista do grupo pesquisado, com respeito, empatia e inserção, o mais íntimo e mais intensamente possível.

[...], lembrando-se que a interação social faz parte da condição e da situação de pesquisa.

Quanto ao grau de envolvimento, aplicaram-se as técnicas não participante e participante. O cenário foi o interior da UBS, em local disponibilizado. O período de observação foi o da realização das entrevistas, que ocorreram em dez turnos, algumas agendadas e outras não. Os comportamentos foram então observados e registrados no diário de campo, ao passo que os sentimentos dos profissionais das equipes em relação ao processo de trabalho foram percebidos durante os depoimentos a partir das entrevistas. As observações feitas durante as entrevistas iam sendo anotadas conjugadamente com a descrição dos cenários; valorizaram-se situações significativas, oportunas e inesperadas, descrevendo-se, então, deduções, sentimentos e impressões pessoais resultantes de conversas informais. Não houve fatores impeditivos para a coleta de dados.

A técnica trabalhada foi análise narrativa de conteúdo; e a modalidade de unidade de análise dos dados escolhida foi a análise categorial. Utilizaram-se categorias analíticas e empíricas. Durante a pré-análise do material, então, identificaram-se estruturas de análise com construção teórica das seguintes categorias analíticas: Formação Profissional, Saúde no Conceito Ampliado, Trabalho em Equipe e Intersetorialidade.

A partir da exploração do material e após a ordenação e classificação dos dados, surgiram como resultados as seguintes categorias empíricas: Retrato dos pesquisados; Formação dos participantes do estudo; O conceito de promoção da saúde e o processo de trabalho em equipe; Fatores mediadores para implementação do Trabalho Intersetorial; Estratégias identificadas para reorientação das práticas na Articulação Intersetorial.

Para garantir o anonimato dos participantes envolvidos no estudo, os nomes dos entrevistados foram substituídos por códigos alfanuméricos compostos pelas letras iniciais da categoria de ator-chave - informante privilegiado (IP), profissional de nível superior (PNS) e profissional de nível técnico (PNT) seguidos do número de ordem da entrevista.

Para executar o trabalho de campo, o projeto da pesquisa seguiu as normas éticas que enfatizam a relevância do consentimento livre e esclarecido, foi encaminhado e submetido ao Comitê de Ética e Pesquisa (CEP) da Escola Nacional de Saúde Pública Sergio Arouca da Fundação Oswaldo Cruz (Ensp/Fiocruz), que recebeu parecer favorável $n^{\circ} 178.294$.

\section{Resultados}

\section{Perfil dos pesquisados}

A população estudada foi de 34 participantes, dentre eles 25 eram do sexo feminino e 9 do sexo masculino. A feminização do trabalho na saúde entre os profissionais das equipes 
é comprovada na pesquisa, que registrou $73.52 \%$ de participantes do sexo feminino.

As motivações para os pesquisados optarem por trabalhar na ESF originaram, com percentuais iguais, as seguintes respostas: trabalhar para subsistência e trabalho com um enfoque social.

O tempo médio de trabalho da equipe de saúde foi de 5,1 anos, sendo a categoria ACS de maior tempo médio de trabalho, com 7,3 anos. Com relação à vinculação trabalhista, apenas quatro profissionais tinham vínculo de trabalho estatutário.

Com relação à escolaridade, 14 profissionais tinham formação no ensino superior; nove profissionais apresentavam desvio de função, sendo cinco com nível de escolaridade superior ao exigido na função, o que acrescenta conhecimento às práticas de trabalho.

\section{Formação dos participantes do estudo}

O curso introdutório na ESF é um instrumento valoroso de informações sobre os princípios e características do processo de trabalho, consideradas atribuições fundamentais comuns e específicas dos profissionais. A pesquisa mostrou que a maioria dos 34 profissionais, 26 (76,47\%), realizaram o curso.

Realidades importantes foram evidenciadas, tais como a única categoria em que todos os profissionais realizaram o curso foi a de ACS; e os agentes de vigilância, embora façam parte das equipes há dois anos, não realizaram o curso introdutório.

Relacionando os cursos de pós-graduação dos atores envolvidos na pesquisa, constatou-se que uma enfermeira e um cirurgião dentista estavam realizando o curso de especialização em Saúde da Família; o outro cirurgião-dentista cursava a especialização em Saúde Pública. Dentre os enfermeiros, encontrou-se especialização em Saúde da Mulher, Saúde do Trabalho, Oncologia, Centro Cirúrgico, Neonatologia e Obstetrícia. $\mathrm{O}$ gestor da unidade se especializava em
Gestão em Saúde da Família. A pesquisa revelou também que não havia médicos titulados em Medicina de Família e Comunidade, embora um dos profissionais trabalhasse no modelo ESF desde sua condição de monitor na graduação. No nível médio, os três agentes de vigilância em saúde realizaram curso de vigilância em saúde.

\section{O conceito de promoção da saúde e o processo de trabalho em equipe}

O conceito de promoção da saúde obteve uma percepção positiva dos profissionais, que pode ser resumida na seguinte fala

É quando você informa da situação de saúde de um cidadão, [...] e você começa a informar ao cidadão o que é a saúde pra ele, como a saúde se completa, como a saúde se faz ou se tem para ele. (PNT13).

Inferiu-se então, pelos dados primários produzidos a partir das entrevistas, que a concepção de saúde ampliada relacionada com os DSS é bem entendida pela equipe, dado que reconhecem a importância do trabalho intersetorial. A ESF é o lócus oportuno para assegurar o desenvolvimento dessa prática ao trabalhar com vinculação, territorialização, responsabilização, resolutividade e integralidade das ações, contribuindo, assim, para melhor qualidade de vida.

A intenção da equipe era resgatar o trabalho voltado à prática da promoção da saúde e estar mais comprometida com essa atividade fomentando o diálogo e a participação, características que se tornaram pouco presentes, o que levou a equipe a estimular a motivação, relação, interação e potencial da autonomia dos sujeitos.

Instrumento das práticas de trabalho para tomada de decisão e aferição de resultados, a avaliação das ações de promoção ainda apresentava incipiente utilização por parte dos profissionais das equipes e era pouco expressiva em relação à participação 
da comunidade, o que era importante para a transformação social. Evidenciou-se também a dificuldade das equipes no planejamento de ações, prática que se apresentou limitada e descontínua.

O estudo mostrou, ainda, que a equipe de saúde bucal não desenvolvia o trabalho em equipe articulado com as EqSFs, fato que pode ser resumido pelo seguinte depoimento:

Olha, especificamente na Saúde Bucal, acho que a gente tem muita dificuldade de se integrar com os outros profissionais [...] de onde isso vem, das equipes de saúde bucal terem chegado depois na Estratégia Saúde da Família e não fazerem parte da equipe básica, mas de um modo geral, não só aqui. [?] É a equipe e a 'Odonto', [...], então eu não consigo ver muito a facilidade e a integração. [...]. Uma coisa que me incomoda, eu preciso estar integrada ao trabalho de toda a equipe, eu tenho que saber um pouco de pré-natal, tenho que entender de tuberculose, [...], mas os outros profissionais não precisam entender nada de Saúde Bucal. [...]. Eu não vejo nada que facilita esta integração da saúde bucal com a equipe, [...]. Até na cabeça da gestão, na cabeça dos outros profissionais [...]. (PNS8).

Vários fatores exercem influência na relação do trabalho em equipe, e um deles descrito pelos profissionais foi o critério de produtividade exigido para alcance do cumprimento das metas e indicadores na obtenção de resultados. Algumas entrevistas mostraram a interferência desta atividade no processo de trabalho das equipes na lógica da saúde da família, como a seguinte:

[...] Hoje, a gente não tem mais promoção da saúde dentro da Estratégia, a gente está reduzido a número, infelizmente esta é uma realidade nossa. Quando eu entrei aqui no PSF [Programa Saúde da Família], a gente conseguia ter uma atenção com o paciente, [...], hoje eu já não posso fazer isto, porque senão eu não consigo dar o número que eles querem e me punirão de alguma forma por baixa produção. (PNT3).
Assim, constatou-se redução das atividades de promoção da saúde, fator restritivo responsável por menor articulação das ações intersetoriais, interferindo no processo de trabalho das equipes, no cumprimento das cláusulas desse novo modelo de contrato de gestão estabelecido entre a Secretaria Municipal de Saúde do Rio de Janeiro (SMSRJ) e a Organização Social de Saúde (OSS) responsável pela Área de Planejamento (AP) no período do estudo - e no desempenho dos critérios de produção adotados para trabalho sob indicadores de acompanhamento, avaliação e metas para os serviços de saúde (RIO DE JANEIRO, 2011).

A equipe sinalizou que, para exercer suas ações, deve usufruir de condições estruturais adequadas e de uma gestão atuante, social, que amplie as práticas intersetorial e interdisciplinar, e estimule a mobilização social. Percebe-se uma gestão em contraposto à gestão social sem estar norteada pelas necessidades de saúde da população.

A implementação das atividades de promoção da saúde e prevenção de doenças não são tão mais atribuídas às equipes, o que evidencia o modelo do gerencialismo com retomada de ações verticalizadas, centradas no assistencialismo. Esse modelo demanda em ações pouco integradas ao processo de trabalho e diminuição do grau de autonomia profissional. Percebe-se, com isso, fragilização de um dos fundamentos da Atenção Primária à Saúde (APS), que é a vinculação entre equipe e população adscrita, gerando influência direta sobre a longitudinalidade do cuidado.

As relações interpessoais desarticuladas e não coesas percebidas entre as equipes contribuíram como fatores estressores da satisfação no trabalho e, consequentemente, influencia a qualidade do trabalho executado; fatores de abstenção; queda da produção do trabalho e a rotatividade, principalmente da categoria profissional médica. A equipe de saúde enquadrou-se no tipo 'equipe agrupamento', revelando um fator de interferência limitante no processo de trabalho. 
Um fator facilitador importante para o trabalho em equipe estava relacionado à construção da alteridade entre os participantes envolvidos na pesquisa. Identificouse o reconhecimento e o respeito ao outro como um estímulo ao trabalho partilhado, percebendo-se também relações não articuladas associadas ao processo de trabalho.

\section{Fatores mediadores para implemen- tação do trabalho intersetorial}

O entendimento do conceito de intersetorialidade é apontado na fala a seguir.

Então, eu fiz parte de um grupo aqui dentro da comunidade que se chama Grupo Articulador Local, que foi o Unicef junto com a prefeitura que se organizaram em prol da criança e adolescente, a partir dali eu vi que a intersetorialidade, ela funciona e funciona bem quando a gente tem objetivos em comum. (PNT10).

Para efetivação da integralidade da atenção é importante que as equipes de saúde estejam estruturadas e articulem-se entre si, bem como com agentes de outros setores. Os depoimentos declaravam que a integralidade das ações carecia de continuidade e comprometimento junto à comunidade para trabalhar sua autonomia e conscientização.

Ainda que o trabalho intersetorial seja uma meta a ser alcançada pelas equipes de saúde, na sua percepção sobre essa prática de trabalho observou-se sensação de insatisfação e impotência, pois consideram seu trabalho ineficiente, mesmo com algumas iniciativas de estabelecimento de ações intersetoriais.

Também foram priorizados problemas vinculados ao desenvolvimento sustentável (água tratada, lixo, situações de risco). Os setores da educação, desenvolvimento social, meio ambiente e defesa civil parecem ser os parceiros mais comuns nas ações intersetoriais das práticas de promoção da saúde, mas a maioria são ações informais, sem planejamento prévio e geralmente coordenadas por apenas um setor (WESTPHAL; MENDES, 2000).

O estudo de Ornelas e Teixeira (2015) que debate a intersetorialidade na experiência do Projeto Teias-Escola Manguinhos, também reforça tal observação, insuficiência de diálogo entre os setores. Desse modo a articulação intersetorial, de fato, não se consolida.

Em relação à utilização do instrumento colegiado gestor, alguns depoimentos foram favoráveis e outros não. Observou-se que entrevistados envolvidos no controle social tinham uma atitude positiva, porém percebiam de forma negativa a visibilidade do colegiado, demonstrando desapontamento e impotência em relação à insuficiente utilização desta ferramenta. Mesmo com opiniões diversificadas, notou-se que esse instrumento era avaliado pelos profissionais.

Atualmente evidencia-se a importância do fortalecimento da autonomia do coletivo para a tomada das decisões. Nesta pesquisa, as próprias equipes, do mesmo modo que a comunidade, encontram dificuldades em exercer sua cidadania no que diz respeito à participação no controle social, assim reforçando a pouca representatividade do colegiado gestor, descrito no depoimento a seguir:

O colegiado é mais participativo na parcela dos moradores do que da própria unidade. A unidade ainda vê o colegiado como uma supervisão, gente de fora que quer se meter no nosso trabalho, então, os profissionais vão um pouco armados pra reunião, vão questionar nosso trabalho [...]. (IP).

Reconheceram-se depoimentos de desesperança quanto à mobilização e vocalização comunitária na defesa de suas necessidades:

A comunidade, pelo contrário, não tem voz, acho que a comunidade tem que participar mais, e não ficar só esperando que as pessoas tragam as soluções. Até porque, nem sempre as soluções que são trazidas são suficientes, ou são satisfatórias para o que realmente a comunidade está precisando. (PNT12). 
A gestão é considerada pelas equipes de saúde um elo entre elas e os demais níveis de atenção, e a pesquisa detectou que a gestão lida com poucos recursos para desempenhar este trabalho. É necessário proporcionar meios adequados às equipes e à gestão para executarem suas ações, com influência direta sobre a produção e qualidade do trabalho em saúde. Dificuldades burocráticas foram detectadas, como ausência ou desconhecimento de como estimular financiamento de ações intersetoriais para concretizá-las.

\section{Estratégias apontadas para reorien- tação das práticas na articulação intersetorial}

O trabalho com práticas educativas de promoção da saúde e a qualificação profissional foram ressaltados como importantes estratégias para reorientação de práticas. Nesse contexto, pode-se incluir a Educação Permanente em Saúde (EPS), uma prática de ação educativa embasada na problematização do processo de trabalho em saúde e que tem como objetivo a transformação das práticas profissionais face às necessidades de saúde das pessoas e das populações (BRASIL, 2009).

EPS se relaciona com a concepção de integralidade na articulação de práticas de promoção, prevenção e recuperação da saúde, na concepção ampliada de saúde, originadas das necessidades de saúde, envolvendo interdisciplinaridade, multidisciplinaridade e intersetorialidade (MENDONÇA, 2007).

As opiniões dos entrevistados se mostraram positivas quanto à mudança no processo de formação de recursos humanos em saúde com enfoque nas necessidades de saúde da população do território.

Eu acho que os profissionais teriam que ser meIhores capacitados na sua formação, a gente tinha que ter tempo realmente para gente montar mesmo um plano de ação, de estudar. Que a gente aqui [...] eu não tenho tempo, eu não consigo, pra melhorar, porque a demanda é muito grande, [...] A rotatividade de profissionais é muito grande. Acaba que, às vezes, você está só, atende só, [...]. (PNS4).

\section{Discussão}

É notável a participação do gênero feminino no setor saúde, segundo estudo realizado por Machado et al. (2010) por meio de dados censitários levantados foi mostrado que são quase $70 \%$ de participação feminina no setor saúde, trabalho considerado uma 'atividade feminina', sendo $61,7 \%$ em categorias profissionais de nível superior e, um número maior ainda, $73,7 \%$ nos estratos de nível médio e elementar. A feminização do trabalho na saúde entre os profissionais das equipes na pesquisa confirma os dados de Machado et al. (2010), com percentagem de 73,52\%.

A promoção da saúde é considerada uma estratégia mediadora entre pessoas e ambiente, e visa a aumentar a participação dos sujeitos e da coletividade na modificação dos determinantes do processo saúde-doença e a promover a equidade.

Tavares et al. (2009) citam estudo com ações centradas na promoção da saúde, planejadas para territórios de vulnerabilidade social que apresentaram resultados impactantes na gestão intersetorial a partir da realização do diagnóstico participativo e integrado das necessidades e potencialidades locais, criação de espaços de trocas e negociações e da elaboração de uma agenda de ações compartilhadas priorizando o monitoramento e avaliação das ações.

As ações de promoção da saúde têm sua maior expressão quando avaliadas, contribuindo para a democratização institucional e para o enfrentamento dos problemas com tomada de decisões. É esperado que a avaliação esteja vinculada ao planejamento de ações que privilegie as necessidades de saúde da população, embasado na avaliação 
de indicadores, na organização de eventos, no fortalecimento e capacitação das equipes de saúde para trabalhar com as ações de promoção da saúde, incorporando o trabalho intersetorial. Percebe-se que a equipe de saúde ainda desenvolve ações sem realizar planejamento e avaliação das ações.

$\mathrm{Na}$ orientação para um bom resultado avaliativo, a Organização Mundial da Saúde (OMS) estabeleceu quatro aspectos para avaliação de iniciativas de promoção da saúde: Participação social dos atores envolvidos; Múltiplos campos disciplinares; Capacitação dos participantes e Adequação das ações se necessárias (MOYSÉS ET AL., 2004).

Nas relações do grupo pesquisado, os estressores percebidos foram a falta de coesão e a diminuição da satisfação no trabalho, que influenciavam diretamente na qualidade do trabalho executado. Segundo Martins (2003), a oportunidade da relação positiva com outros é uma variável considerada quando se reporta à satisfação no trabalho e sua relação com a motivação, identificação e produtividade no trabalho ou qualidade de vida.

É preciso compreender as práticas de trabalho como processos de revisão do próprio trabalho, portanto, processos de problematização e aprendizado, que se manifestam com relações de trocas e de conflitos de posições e de poder.

Peduzzi (2001) propôs duas modalidades de equipes: a primeira, equipe integração, que atua visando à integralidade de ações de saúde com articulação e partilhamento de decisões; e a segunda, equipe agrupamento, na qual a população pesquisada se encontra, que mostra uma comunicação externa ao trabalho e pessoal, com autonomia plena, de caráter independente. $\mathrm{O}$ tipo de equipe encontrado refletia na ausência de responsabilidade coletiva do trabalho e no baixo grau de interação profissional.

A forma de vínculo de trabalho encontrada convergiu para a categoria celetista na maioria dos profissionais, e este fato influenciou na alta rotatividade nas equipes, comprovando a fala de Gil (2005) em relação ao comprometimento de uma característica essencial na lógica de trabalho da estratégia, que é a formação de vínculos.

A constatação da sensação de impotência evidenciada na equipe em relação ao trabalho intersetorial vem a confirmar o já previsto por Mendes (1996), ou seja, as equipes não executam rotineiramente ações intersetoriais e teriam também seus esforços integrativos limitados, pois estes estariam na dependência das capacidades de condução da gestão.

O estudo de Moretti (2010) relata, ainda, que a ação intersetorial é um processo de aprendizagem e determinação dos sujeitos e deve resultar em uma gestão integrada, capaz de responder com eficácia à solução de problemas do território sob sua responsabilidade.

No que diz respeito à participação no controle social, nem as próprias equipes nem a comunidade tinham dificuldades em exercer sua cidadania. Muitos pesquisados desconheciam a função do colegiado gestor. Para poder manter a sustentabilidade de uma comunidade organizada, é preciso fortalecer a autonomia para poder adequar as ações às condições extremamente diferenciadas que as populações enfrentam.

A participação e o controle social são considerados elementos fundamentais nas ações sanitárias, entendendo-se que a realidade social exige a construção de poder coletivo de necessidades originadas de um indivíduo, grupo, ou de uma população, construídas a partir de diferentes saberes, setores e interesses que permeiam a saúde e outros protagonistas envolvidos.

A participação social é um requerimento essencial para desenvolvimento e organização local, integrados e sustentáveis, a partir do fomento à mobilização para trabalhar as reivindicações, determinar as necessidades e os problemas prioritários, e também escolher alternativas para enfrentamento e tomada de decisões (ALBUQUeRQUE; STOTZ, 2004). Dentre os objetivos específicos da ESF está o 
de "estimular a organização da comunidade para o efetivo exercício do controle social” (BRASIL, 1997, P. 10).

Trabalhar com práticas educativas de promoção da saúde tem por objetivo interferir na realidade de determinada situação social, que se expressa por meio da organização e empoderamento contínuo da população ante a realidade concreta. Estas práticas de trabalho podem ser estimuladas pelos profissionais de saúde, levando a população, em geral, a identificar um novo conceito sobre o processo saúde-doença-cuidado. É o exercício da cidadania, desse modo atuando como fatores facilitadores nas articulações intersetoriais.

Incentivos à reestruturação das grades curriculares nos cursos de graduação e pós-graduação das instituições de ensino e pesquisa da área de saúde, com formação diretiva à interdisciplinaridade e com o objetivo de desestimular relações de poder entre disciplinas, são essenciais; é a abordagem do processo saúde-doença-cuidado de maneira ampliada (AZEVEDO ET AL., 2012). Os pesquisados manifestaram a necessidade de participação em práticas educativas, educação em saúde, educação permanente em saúde ou educação continuada, mas têm dificuldade de construir ações devido à sobrecarga de trabalho.

A formação de recursos humanos em saúde deve ser voltada para estimular uma reflexão crítica e produtiva; estar em consonância com o serviço; considerar as necessidades de saúde e o perfil epidemiológico da população do território, aplicando a humanização e objetivando a transformação da realidade (ERDMANN ET AL., 2009).

Estudos (GIOVANELLA ET AL., 2009) mostraram que, apesar de constatado o crescimento da integração da rede de serviços de saúde, a insuficiência de uma adequada formação profissional contribui para a incipiência da ação intersetorial pelos profissionais.

A pesquisa revelou um diferencial quando, a partir da ordenação dos dados primários coletados, identificou a categoria
'Estratégias para reorientação das práticas na articulação intersetorial', assim evidenciando que a equipe desejava melhoria da sua prática de trabalho.

\section{Proposições dos pesquisados}

O desafio do estudo foram as propostas da equipe de saúde de ações de reorientação das práticas do trabalho intersetorial com o direcionamento do profissional para o exercício de tomada de decisão. As proposições construídas foram agrupadas em cinco temas e estão listadas a seguir:

I - Qualificação profissional

Capacitações técnicas foram planejadas e seriam selecionadas a partir das fragilidades identificadas pela equipe, na lógica da interdisciplinaridade das ações para os profissionais da atenção e da gestão; Participação no curso Introdutório citado nas entrevistas como metodologia de geração de conhecimentos.

II - Processo de trabalho em equipe

Organização das práticas de trabalho foi proposta com a inclusão do reforço da mobilização comunitária, garantia da longitudinalidade do cuidado, fortalecimento da responsabilização e empoderamento profissional favorecendo a tomada de decisão e resolutividade das ações; Reestruturação da porta de entrada com resolutividade na atenção a demandas provenientes do território ou de outros níveis de atenção, com escuta qualificada fundamentada na política de humanização visando à melhoria das ações de promoção da saúde intra e intersetorial e do sistema de referenciamento; Estímulo à interação entre gestão e atenção, que busca, desse modo, o direito de nível mais elevado possível de saúde com dignidade, equidade e solidariedade, valores reconhecidos da APS.

III - Ferramentas das práticas de trabalho

Utilização de mecanismos de planejamento, monitoramento e avaliação visando à 
sustentabilidade das ações e fortalecimento do vínculo; Incentivo à EPS como transformadora da prática em saúde; Participação de encontros entre equipe e família para, a partir deles, promover trocas de experiências e saberes entre todos os sujeitos.

IV - Participação Comunitária

Fomento à participação proativa do controle social pela população, potencializando sua autonomia e exercendo seus direitos como cidadã; Fortalecimento do desempenho do controle social.

\section{V - Construção da Rede}

Incentivo à construção de uma rede de atenção à saúde conectada e articulada, fortalecendo processos participativos, fundamentados nas necessidades de saúde apontadas; Reuniões regulares com parceiros foram sugeridas também como momento de trocas de saberes e práticas que demandassem planejamento, monitoramento e avaliação das ações coletivas; Rede de comunicação conectada, dialógica estimulando pessoa, grupo, setores da saúde e outros, originando um trabalho em equipe coeso e integrado, todos visando ao mesmo objetivo.

\section{Conclusão}

O objetivo desta pesquisa foi o de contribuir para a reflexão sobre as articulações desenvolvidas para a implementação do trabalho intersetorial pelas EqSFs de uma UBS do município do Rio de Janeiro.

$\mathrm{Na}$ reorganização do modelo de saúde por meio da ESF, a rede de saúde assume a mudança do paradigma assistencial estimulando a produção social da saúde; amplia a ação unisetorial ou intrasetorial para intersetorial; muda de um sistema de saúde restritivo para garantia de acesso universal. Desse modo, o modelo se torna um instrumento-chave para o empoderamento, para a gestão social.

Nesse contexto, a promoção da saúde atua em uma lógica ampliada, fomentando a autonomia e a participação das comunidades e fortalecendo as ações intersetoriais articuladas, promotoras de comportamento e estilo de vida saudáveis em relação ao cuidado à saúde dos sujeitos.

Percebeu-se na pesquisa que a intersetorialidade, ainda que não ocorresse de forma efetiva, foi entendida como reconhecimento de prática integrada de trabalho em equipe, considerando-se que o setor saúde, sozinho, não é capaz de implementar práticas de promoção da saúde, uma vez que envolvem os determinantes sociais da saúde. A intersetorialidade ainda se coloca, para a equipe, como um desafio que visa a garantir a execução de políticas sociais que respondam às desigualdades e iniquidades.

Propostas de reorientação das práticas de trabalho foram discutidas pelos pesquisados como meio de potencializar o trabalho intersetorial. Deve-se reconhecer, no entanto, que o foco para qualificar formação e trabalho, para também poder desenvolver a ação intersetorial, deve ser o da integração entre ensino, serviço e gestão do sistema de saúde, de forma a compor também uma gestão participativa e compartilhada.

O conceito e a prática da intersetorialidade precisam ser inseridos na rotina de gestores e equipes de saúde para que, paulatinamente, adquiram habilidades no desenvolvimento de ações de promoção da saúde realmente impactantes, almejando melhoria das condições de saúde da população.

\section{Colaboradores}

Denise Alves José da Silva contribuiu na concepção do tema, na organização e planejamento da pesquisa, construção da dissertação e na revisão crítica do conteúdo.

Maria de Fátima Lobato Tavares contribuiu na organização e planejamento do trabalho, na análise e interpretação dos dados; e na aprovação da versão final do manuscrito. 


\section{Referências}

ALBUQUERQUE, P. C.; STOTZ, E. N. A educação popular na atenção básica à saúde no município: em busca da integralidade. Interface (Botucatu), Botucatu, v. 8 , n.1 5, p. 259-274, mar./ago. 2004.

\section{AZEVEDO, E.; PELICIONI, M. C. F.; WESTPHAL,}

M. F. Práticas intersetoriais nas políticas públicas de promoção de saúde. Physis, Rio de Janeiro, v. 22, n. 4, p. 1333-1356, 2012.

BRASIL. Ministério da Saúde. Saúde da Família: uma estratégia para a reorientação do modelo assistencial. Brasília, DF: Ministério da Saúde, 1997.

Ministério da Saúde. Portaria nº 2.446, de 11

de novembro de 2014. Redefine a Política Nacional de Promoção da Saúde (PNPS). Diário Oficial [da] União, Brasília, DF, 2014. Disponível em: <http://bvsms.saude. gov.br/bvs/saudelegis/gm/2014/prt2446_11_11_2014. html>. Acesso em: 17 out. 2016.

Ministério da Saúde. Secretaria de Gestão do Trabalho e da Educação na Saúde. Glossário temático: gestão do trabalho e da educação na saúde. Brasília, DF: Ministério da Saúde, 2009. (Normas e Manuais Técnicos, A).

Ministério da Saúde. Secretaria de Vigilância em Saúde. Política Nacional de Promoção da Saúde. 3. ed. Brasília, DF: Ministério da Saúde, 2010.

\section{COMISSÃO NACIONAL SOBRE DETERMINANTES} SOCIAIS DA SAÚDE (CNDSS). As causas sociais das iniquidades em saúde no Brasil: relatório final da Comissão. Rio de Janeiro: CNDSS, 2008. Disponível em: <http://bvsms.saude.gov.br/bvs/publicacoes/ causas_sociais_iniquidades.pdf $>$. Acesso em: 22 maio 2014.

ERDMANN, A. L. et al. O olhar dos estudantes sobre sua formação profissional para o Sistema Único de Saúde. Acta paul. enferm., São Paulo, v. 22, n. 3, p. 288 294, 2009.

FRANCO, T.; MERHY, E. PSF: Contradições e novos desafios. Conferência Nacional de Saúde On-Line. [Online], 1999. Disponível em: <http://www.uff.br/ saudecoletiva/professores/merhy/artigos-17.pdf $>$. Acesso em: 17 out. 2016.

GIL, C. R. R. Formação de recursos humanos em saúde da família: paradoxos e perspectivas. Cad. saúde pública, Rio de Janeiro, v. 21, n. 2, p. 490-498, abr. 2005.

GIOVANELLA, L. et al. Saúde da família: limites e possibilidades para uma abordagem integral de atenção primária à saúde no Brasil. Ciênc. saúde coletiva, Rio de Janeiro, v. 14, n. 3, p. 783-794, 2009.

JUNQUEIRA, L. A. P. Intersetorialidade, transetorialidade e redes sociais na saúde. Rev. adm. Pública, Rio de Janeiro, v. 34, n. 6, p. 35-45, nov./dez. 2000.

MACHADO, M. H. et al. Análise da força de trabalho do setor saúde no Brasil: focalizando a feminização. Divulgação em Saúde para Debate, Rio de Janeiro, n. 45, p. 54-70, maio 2010

MANCE, E. A. Emmanuel Lévinas e a alteridade. Revista Filosofia PUC-PR, Curitiba, v. 7, n. 8, p. 23-30, abr. 1994.

MARTINS, M. C. A. Situações indutoras de stress no trabalho dos enfermeiros em ambiente hospitalar. Millenium, Viseu, v. 28, 2003. Disponível em: <http:// www.ipv.pt/millenium/Millenium28/18.htm>. Acesso em: 17 out. 2016

MARTINS, P. C. et al. Democracia e empoderamento no contexto da promoção da saúde: possibilidades e desafios apresentados ao Programa de Saúde da Família. Physis, Rio de Janeiro, v. 19, n. 3, p. 679-694, 2009.

MENDES, E. V. Uma agenda para a saúde. São Paulo: Hucitec, 1996

MENDONÇA, F. F. Formação de facilitadores de educação permanente em saúde: Percepções de tutores 
e facilitadores. 2007. 124 f. Dissertação (Mestrado em Saúde Coletiva) - Universidade Estadual de Londrina, Londrina, 2007.

MINAYO, M. C. S. O desafio do conhecimento: pesquisa qualitativa em saúde. 12. ed. São Paulo: Hucitec, 2010.

MORETTI, A. C. et al. Intersetorialidade nas ações de promoção de saúde realizadas pelas equipes de saúde bucal de Curitiba (PR). Ciênc. saúde coletiva, Rio de Janeiro, v. 15, supl. 1, jun. 2010.

MOYSÉS, S. J.; MOYSÉS, S. T.; KREMPEL, M. C. Avaliando o processo de construção de políticas públicas de promoção de saúde: a experiência de Curitiba. Ciênc. saúde coletiva, Rio de Janeiro, v. 9, n. 3, p. 627-641, jul./set. 2004.

ORNELAS, A. L.; TEIXEIRA, M. G. C. Intersetorialidade ou diálogos setoriais? Reflexões a partir da experiência do Projeto Teias-Escola Manguinhos, Rio de Janeiro. Saúde em Debate, Rio de Janeiro, v. 39, n. 106, p. 659-670, jul./set., 2015.

PEDUZZI, M. Equipe multiprofissional de saúde: conceito e tipologia. Rev. saúde pública, São Paulo, v. 35, n. 1, p. 103-109, 2001.
RIO DE JANEIRO (Município). Secretaria de Saúde. Contrato que entre si celebram o município do Rio de Janeiro, por intermédio da Secretaria Municipal da Saúde e Defesa Civil - SMSDC e o Instituto Social

Fibra, com vistas à regulamentação do desenvolvimento e execução das ações e serviços de saúde, dos equipamentos destinados a Saúde de Família no âmbito da área de planejamento 2.2 [mimeo], 2011. Disponível em: <http://www.rio.rj.gov.br/dlstatic/10112/2274083/ DLFE236323.pdf/ContratodeGestaoFibra2..2..pdf>. Acesso em: 17 out. 2016.

TAVARES, M. F. L. et al. Articulação intersetorial na gestão para a promoção da saúde. In: OLIVEIRA, R. G. (Org.). Qualificação de gestores do SUS. Rio de Janeiro: EAD; Ensp, 2009.

WESTPHAL, M. F.; MENDES, R. Cidade saudável: uma experiência de interdisciplinaridade e intersetorialidade. Rev. Adm. Pública, Rio de Janeiro, v. 34, n. 6, p. 47-61, 2000.

Recebido para publicação em abril de 2016

Versão final em agosto de 2016

Conflito de interesses: inexistente

Suporte financeiro: não houve 